Florian Hartmann (dir.), Brief und Kommunikation im Wandel. Medien, Autoren, und Kontexte in den Debatten des Investiturstreits

\title{
Kevin Schmidt
}

\section{OpenEdition}

1 Journals

Édition électronique

URL : http://journals.openedition.org/ifha/8858

DOI : $10.4000 /$ ifha. 8858

ISSN : 2198-8943

Éditeur

IFRA - Institut franco-allemand (sciences historiques et sociales)

Référence électronique

Kevin Schmidt, «Florian Hartmann (dir.), Brief und Kommunikation im Wandel. Medien, Autoren, und Kontexte in den Debatten des Investiturstreits », Revue de l'IFHA [En ligne], Date de recension, mis en ligne le 02 novembre 2017, consulté le 24 septembre 2020. URL : http://journals.openedition.org/ifha/8858 ; DOI : https://doi.org/10.4000/ifha.8858

Ce document a été généré automatiquement le 24 septembre 2020.

(CIFHA 


\section{Florian Hartmann (dir.), Brief und Kommunikation im Wandel. Medien, Autoren, und Kontexte in den Debatten des Investiturstreits}

Kevin Schmidt

\section{RÉFÉRENCE}

Florian Hartmann (dir.), Brief und Kommunikation im Wandel. Medien, Autoren, und Kontexte in den Debatten des Investiturstreits, Köln-Weimar-Wien: Böhlau (Papsttum im mittelalterlichen Europa, 5), 2016, 401 p., $70 €$ 
La Querelle des investitures (1075-1122) bouleversa profondément l'Occident médiéval. À une Église impériale héritée des Ottoniens et contrôlée directement par le souverain succéda, après le Concordat de Worms, une Église où les chapitres cathédraux eurent désormais le pouvoir d'élire les nouveaux prélats. La séparation entre pouvoir spirituel et pouvoir temporel fut alors actée et le prestige de la papauté renforcé au détriment de la fonction impériale. Le livre dont il est question ici dépasse largement l'épisode connu de la pénitence de l'empereur Henri IV à Canossa pour embrasser la Querelle dans son ensemble en examinant comment discours et modes de communication ont évolué au long de la lutte entre pape et empereur. Il est le

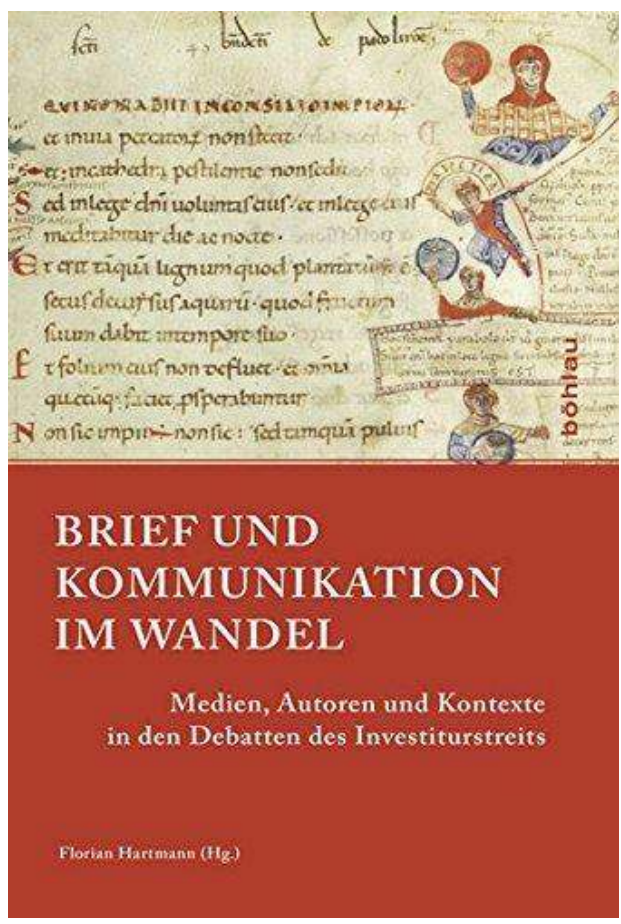
résultat d'un colloque ayant réuni de nombreux spécialistes du sujet à l'Institut für Geschichtswissenschaft de l'université de Bonn en février 2014.

Après une très complète introduction de Florian Hartmann, la première partie de l'ouvrage, axée sur les aspects théoriques et historiographiques, s'ouvre avec l'article de Rudolf Schieffer qui passe en revue les différentes interprétations que l'historiographie a attribuées à la Querelle des Investitures au cours des cent cinquante dernières années. Thomas Wetzstein s'interroge ensuite sur la lettre en tant que moyen de communication aux $\mathrm{XI}^{\mathrm{e}}$ et $\mathrm{XII}^{\mathrm{e}}$ siècles, tout en précisant qu'elle n'est en réalité que la partie écrite du discours, la partie orale restant l'apanage du messager lui-même, qui avait aussi pour ordre de transmettre les informations utiles. Il conclut en soulignant le rôle transitionnel important joué par la Querelle des Investitures dans l'histoire de la communication. Sur la même question, Oliver Münsch évoque, au sein des Streitschriften, l'importance des rumeurs qui, lorsqu'elles sont couchées par écrit, peuvent se diffuser d'autant plus facilement au sein du public. Christian Heinrich revient sur la définition même de Streitschriften et en définit une approche typologique plus précise grâce à plusieurs critères : une longueur raisonnable, une intention, un public-cible et la volonté de s'intégrer au débat. Jochen Johrendt, ensuite, développe le concept de destruction créatrice pour évoquer les nouvelles formes de validation présentes dans les bulles papales. Ce processus découlerait de la réaction des pontifes face à la désignation d'antipapes qui se rattachaient à une tradition établie afin d'assurer leur pouvoir alors que les premiers pouvaient innover en créant des formules originales. Gerhard Lubich compare les lettres d'Henri IV et celles de son fils et note des différences dans la rédaction des adresses : Henri $V$ y incluait un caractère davantage « rassembleur » et public alors que son père mentionnait clairement les destinataires, comme dans une correspondance privée.

La seconde partie de l'ouvrage met l'accent sur les différents types de discours utilisés par plusieurs auteurs liés aux controverses de la Querelle. Mathias Schrör s'intéresse à 
la correspondance de l'évêque Hezilo d'Hildesheim (1054-1079), membre de l'Église impériale qui louvoya entre les deux partis durant les prémices du conflit, et à sa stratégie de communication. Roland Zingg débarque outre-Manche pour s'intéresser aux relations entre l'archevêque de Canterbury et le roi d'Angleterre. Le corpus des lettres d'Anselme (1093-1109) montre qu'il n'y a eu là-bas que des désaccords entre personnes qui ont pu être résolus de manière pragmatique. Wilfried Hartmann revient sur l'idéologie politique du bien connu Sigebert de Gembloux (ca.1030-1112) et lui conteste la paternité du Tractatus de investitura episcoporum. Eugenio Riversi détaille ensuite la vaste et complexe Vita metrica Anselmi de Ranger de Lucques. George Starck étudie également cet auteur en comparant les caractéristiques de son discours avec les écrits d'un des plus célèbres défenseurs du parti impérial, Benzon d'Albe. Nicolangelo D'Acunto s'intéresse ensuite à la forme et aux procédés argumentaires employés par Pierre Damien dans sa vaste correspondance.

Les dernières communications abordent plus particulièrement les arguments mobilisés par les deux partis au cours de certains épisodes de la Querelle. Ainsi Matthias Becher analyse, via la correspondance de Grégoire VII, l'évolution des relations entre ce dernier et Henri IV au cours des deux années précédant sa destitution ordonnée au synode de Worms en janvier 1076. Anja-Lisa Schroll se penche sur les récupérations du schisme de Cadalus déployées dans le cadre de l'opposition entre Grégoire VII et l'antipape Clément III dans les décennies 1080-1090. Klaus Herbers évoque quant à lui la transmission et la récupération des lettres pontificales du IX ${ }^{e}$ siècle, notamment celles de Nicolas $\mathrm{I}^{\mathrm{er}}$ (858-867), au temps de la réforme grégorienne. Enfin, Lotte Kéry présente les différentes collections canoniques réalisées pour servir les buts de la réforme. Pour conclure, F. Hartmann souligne la grande richesse du sujet et les nombreuses études qu'il resterait encore à mener.

Ce livre est le cinquième de la grande collection Papsttum im mittelalterlichen Europa, inaugurée en 2012 avec une étude sur les antipapes et dont la qualité des intervenants et des communications n'est plus à prouver. Par la diversité des personnages et des lieux évoqués, il suscitera l'intérêt des spécialistes de la Querelle des investitures et des $\mathrm{XI}^{\mathrm{e}}$-XII ${ }^{\mathrm{e}}$ siècles mais aussi celui de ceux qu'intéressent les questions de communication au Moyen Âge.

\section{INDEX}

Index chronologique : Moyen Âge

Thèmes : Histoire des États et des pouvoirs ; Histoire religieuse ; Histoire du droit ; Histoire des mentalités ; Histoire des idées 


\section{AUTEURS}

KEVIN SCHMIDT

Université de Liège 